\title{
Assessment of an educational intervention to improve nurses' knowledge of blood pressure measurement
}

\author{
Juliana P. Machado ${ }^{1}$, Eugenia V. Veiga ${ }^{2}$, Paulo A. C. Ferreira ${ }^{3}$, Jose Carlos A. Martins ${ }^{3}$, Elisabeth Atila ${ }^{4}$, Fernanda R. \\ E. Gimenes*2 \\ ${ }^{1}$ University Center of Barão de Mauá, Ribeirão Preto, São Paulo, Brazil \\ ${ }^{2}$ College of Nursing, University of São Paulo, Ribeirão Preto, São Paulo, Brazil \\ ${ }^{3}$ Escola Superior de Enfermagem de Coimbra, Coimbra, Portugal \\ ${ }^{4}$ Mona Vale Hospital, Mona Vale, NSW, Australia
}

Received: June 23, 2017

DOI: $10.5430 /$ jnep.v8n2p56
Accepted: September 26, $2017 \quad$ Online Published: October 17, 2017

URL: https://doi.org/10.5430/jnep.v8n2p56

\begin{abstract}
Background: Accurate blood pressure (BP) measurement is a constant challenge, particularly in intensive care units. Thus, studies focusing on avoiding errors in practices of measuring BP are important to patient safety. The objective was to assess the effects of an educational intervention addressing BP measurement, targeting the theoretical and practical knowledge of nurses from a cardiac unit.

Methods: This quasi-experimental, before-and-after, study was conducted in a large tertiary hospital in Brazil and included all nurses working in that unit (31 nurses, $86.1 \%$ ). Data were collected through two types of assessments: practical and theoretical knowledge of the technique, before-and-after the educational intervention that involved simulation as a teaching strategy. A validated checklist was used for both assessments.

Results: Most participants were female (64.5\%), with an average age of 33.1 years old. Considerable improvement was observed in theoretical and practical knowledge concerning the steps used for BP measurement $(p<.05)$. Considering the total sample, nurses complied with all steps of the BP measurement after educational intervention and the results were considered statistically significant $(p<.05)$.

Conclusions: The educational intervention improved the knowledge of nurses, which may contribute to safer healthcare delivery and error-free BP measurements.
\end{abstract}

Key Words: Blood pressure measurement, Education, Intensive care unit, Knowledge, Simulation

\section{INTRODUCTION}

Hypertension is a worldwide public health problem and keeping blood pressure (BP) within normal levels is crucial to reducing morbidity and mortality. ${ }^{[1]}$ Accurate BP measurement is a constant challenge, particularly in intensive care units (ICU), where decisions are often made in haste and precise vital signs measurement is essential. ${ }^{[2]}$
In the United States, ${ }^{[3]}$ Canada $^{[4]}$ and Europe, ${ }^{[5]}$ the guidelines recommended the use of an automated oscillometric BP measurement device because it is easy to use, it is accurate and it reduces observer errors. ${ }^{[6]}$ In contrast, in Brazil, the auscultatory method is widely used by nurses and other healthcare practitioners to assess BP. ${ }^{[7]}$ This method is specifically indicated for cases of severe arrhythmias because the

*Correspondence: Fernanda R. E. Gimenes; Email: fregimenes@eerp.usp.br; Address: College of Nursing, University of São Paulo, Ribeirão Preto, São Paulo, Brazil. 
oscillometric device may not capture abnormal heartbeats. ${ }^{[8]}$ Thus, the oscillometric device is more commonly indicated for critically ill patients.

Previous research showed that a lack of specific training in BP measurement is a major concern for nurses, especially regarding the proper handling of equipment. ${ }^{[9,10]}$ To date, no other published studies addressing the effects of an educational intervention for BP measurement were identified in the last five years, perhaps due to the automation of the oscillometric method.

A lack of continuing education programs in healthcare services affects the quality of care provided to patients and increases the level of stress for nurses. ${ }^{[11]}$

Due to a lack of studies focusing on avoiding errors in practices of measuring BP and understanding that nurses are key elements in intensive care, the objective was to assess the effects of an educational intervention addressing BP measurement, targeting the theoretical and practical knowledge of nurses from a cardiac unit. Once knowledge gaps are known, educational interventions become feasible strategies for improving practice, when inserted in professional training programs in institutions.

\section{METHOD}

\subsection{Setting}

The study was conducted in a cardiac unit of a large tertiary hospital in Brazil.

\subsection{Design}

A quasi-experimental, before-and-after study with a single group, thus subjects served as their own controls. The study hypotheses was that an education intervention can improve the theoretical and practical knowledge of BP measurement.

\subsection{Study sample}

All nurses working in the cardiac unit were eligible; from a population of 36 nurses, 31 (86\%) agreed to participate in this study.

\subsection{Data collection tools}

Data were collected through two types of assessments. A practical assessment in which the participants had to demonstrate their practical knowledge of the technique by using a checklist of the steps of BP measurement, in accordance with Brazilian guidelines, and an assessment of their theoretical knowledge using a self-reported questionnaire. Both tools were organized in five topics of specific knowledge indirectly associated with BP measurement: preparation of the patient, preparation of the environment, position of the patient, device maintenance, determining and recording values.

Published by Sciedu Press

\subsection{Intervention and assessment}

Data were collected through two types of assessments. A practical assessment in which the participants had to demonstrate their practical knowledge of the technique and an assessment of their theoretical knowledge using a previously validated self-reported questionnare titled CTMI-PA. The participation of each professional was conditioned to voluntary acceptance, after explaining the steps to be followed in the collection of data.

The checklist contains the sequential steps of the indirect measurement of BP as described in the Brazilian guidelines, which are in line with international guidelines. In all, there are 52 steps that range from accommodating the patient in the correct position for the measurement, position of arm, legs and feet, to the auscultation of the Korotkoff sounds and recording the obtained values. It was standardized so there would not be a minimum score as all steps are required. The checklist was submitted for content validation by five specialists from different Brazilian institutions with recognized knowledge on the subject. Semantic validation was then performed by the DISABKIDS $\AA$ method, ${ }^{[12]}$ whose rigor requires the composition of a specific sample, composed of members of the same population, who were duly excluded from the final sample. In the next stage, a pre-test was performed with 30 subjects of similar population, to evaluate the applicability of this checklist. Results from the validation are in process at the time of publication. The final version of the checklist was used in this study.

For the theoretical evaluation, a questionnaire elaborated by these authors was used, containing 20 questions relating to the theoretical basis that supports the steps of BP measurement, and personal characteristics. The questions seek to provide evidence of knowledge about critical points of the indirect measurement, such as the ideal arm height, the position of the legs, and how to record the values obtained, in addition to a proper maintenance and calibration schedule as required for the equipment. This second questionnare, and its validation process, followed a rigorous methodological approach: the questions were first submitted to content validation and pertinence by five experts. After the appropriate adaptations, semantic validation was performed by the DISABKIDS method: ${ }^{[12]}$ the questionnaire was applied to 20 subjects from a sample similar to the study, for possible adjustments in terms or expressions used. After this validation step, the questionnaire was submitted to the test with 30 subjects from a population sample with the same characteristics.

The authors chose not to establish a sufficient or insufficient knowledge score, but the analysis was aimed at comparing 
the knowledge before and after the intervention, as well as evidence of the steps performed without reflection in an automated way or even steps of BP measurement ignored in practice, even though they were cited in theory.

For the execution of the practical activities, a team of collaborators was prepared to act in the collection of the data of the practical evaluation. They were trained through orientations and simulations of activities. Volunteer actors were trained in posture, behavior, responses and standardized attitudes, to be replicated. So, the actor/patient was systematically trained to reproduce identical history for the consultations and to act exactly the same way in all of the consultations. Observers remained in a neutral and anonymous position in the simulation scenario to minimize the Hawthorne effect.

\subsection{Procedure for data collection}

Data collection occurred in two phases, as described:

\section{Phase 1: Pre-intervention practical assessment}

The aneroid technique to indirectly measure BP was assessed before the educational intervention. A nursing consultation was simulated with an actor playing the role of a patient. The assessment was done by a checklist, in a non-participative observation. The practical assessment took place with the professional in the role of a nurse consulting a patient (an actor) for the first time. The professional performed the BP measurement under the primary researcher collaborators's observation, who recorded the steps on a validated checklist. The simulation took place in the hospital itself in a previously designed room where the observer remained in a neutral and non-participative position, outside the professional's view to avoid visual interference during the procedure.

\section{Phase 2: Pre-intervention theoretical assessment}

After the technique was demonstrated, the professional was asked to answer the CTMI-PA questionnaire addressing socio-demographic questions and the stages of the indirect BP measurement as recommended by guidelines.

\section{Phase 3: Educational intervention}

After theory and practice were assessed, an educational intervention, comprised of an explanatory and interactive twohour lesson, was implemented by the primary researcher. The nurses were encouraged to reflect upon the simulation and any gaps they could identify in their knowledge using the arch of problematization method. ${ }^{[13]}$ The content of the lesson was validated by five specialists in nursing education and replicated by the same research. Discussions about the participants' experience were welcomed and they were encouraged to report the key elements of BP measurement. Afterwards the groups rechecked the technical content through

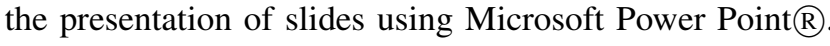

The activity ended with a demonstration of the technique by volunteers from the group itself, interacting with a narration of the stages.

The problematization strategy requires an analysis of a practical situation experienced by the individual, and the simulation of a clinical situation allows for constructive reflections, as required by the method, without exposing patients or professionals to discussions about errors or difficulties. The choice of simulation as a teaching strategy for adult learning was considered as a function of current world trends, as recommended by peak advisory bodies such as the American Heart Association's courses for Advanced Cardiology Life Support (ACLS) and Basic Life Support (BLS). ${ }^{[14]}$ Simulation has been increasingly encouraged by several areas of knowledge over the last few years. The same educational strategy has been used in continuing education programs in many healthcare institutions worldwide. In addition, the high fidelity simulation, in the "clinical situation with actors" modality, has been shown to be an effective, low cost strategy that promotes interpersonal interactions.

\section{Phase 4: Post-intervention practical assessment}

This phase was implemented up to 15 days after the educational intervention and it consisted of a practical assessment of indirect BP measurement, strictly following the same steps of the pre-intervention assessment, recorded by a nonparticipant observer in the same setting.

\section{Phase 5: Post-intervention theoretical assessment}

The questionnaire used for theoretical assessment (CTMIPA) was applied in this phase following the same procedure used in the pre-intervention theoretical assessment, in order to enable comparison among variables before and after the education interview.

\subsection{Statistical analysis}

For data analysis, the paired $t$ test was used for the variables with normal distributions (Shapiro-Wilk test) and the Wilcoxon test for matched samples was used for the remaining variables for comparisons before and after the interven-

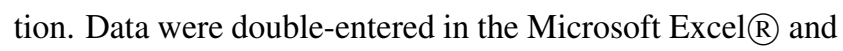
processed in the Statistical Package for the Social Sciences $\mathbb{R}$ (SPSS) version 10.0 with a two-tailed and level of significance of $p<.05$.

\subsection{Ethical considerations}

The study was approved by the Research Ethics Committee of the University of São Paulo at Ribeirão Preto College of Nursing (Protocol no. 1418/2011), according to the National Council of Ethics in Research of the Brazilian Ministry of Health. Participants were informed of the research and 
asked to voluntarily sign the consent form. They were also informed that the results will be used for publication and researchers guaranteed their confidentiality and anonymity.

\section{Results}

\subsection{Personal characteristics}

The study sample consisted of 31 participants (12 registered nurses and 19 nursing technicians). The majority was female $(64.5 \%)$, with an average age of 33.1 years old. Table 1 shows the personal characteristics of the participants.

Table 1. Sample characteristics $(n=31)$

\begin{tabular}{lll}
\hline Socio-demographic variables & $\mathbf{n}$ & \% \\
\hline Age & 14 & 45.2 \\
Up to 30 years old & 12 & 38.7 \\
From 31 to 40 years old & 5 & 16.1 \\
From 41 to 48 years old & & \\
Experience in current function & 4 & 12.9 \\
Up to 1 year & 10 & 32.3 \\
From 2 to 5 years & 17 & 54.8 \\
6 years or more & & \\
\hline
\end{tabular}

All participants reported having participated in some educational activity involving indirect BP measurement in their course. Eleven (35.4\%) participants had previous training in BP measurement after completing their basic education program. From those, six (54.5\%) reported that training took place more than one year ago.

\subsection{Nurses' practical knowledge of blood pressure mea- surement}

An observational grid was used to verify the frequency in which the steps concerning the assessment of practical knowledge of BP measurement were followed. Table 2 shows the results of the pre-post comparison.

\subsection{Nurses' theoretical knowledge of blood pressure measurement}

After the practical assessment, the theoretical knowledge concerning the BP measurement was assessed through a specific questionnaire. There are other answers in the preintervention assessment concerning the preparation of the patient that were not included in the guidelines, such as: check for the intake of drugs or medications (58.1\%); check whether the patient is hypertensive (35.5\%); and check whether the patient is in pain (19.4\%). Additionally, there are other characteristics concerning the preparation of the ideal setting such as good lighting (25.8\%) and appropriate accommodation (19.4\%). In regards to the maintenance of devices and defects that justify their disposal, the professionals highlighted air leaks (67.7\%) and non-adhesive arm cuff $(61.3 \%)$ before the intervention. After this, both answers appear in $77.4 \%$ of the cases. Table 3 shows all results preand-post-interview. The results show that the theoretical and practical knowledge of nurses improved after the educational intervention addressing the indirect BP measurement.

Table 2. Comparison of the frequency of steps correctly performed in indirect BP measurement by nursing professionals in the practical assessment $(\mathrm{n}=31)$

\begin{tabular}{|c|c|c|c|c|c|c|c|}
\hline \multirow{2}{*}{ Steps of BP measurement } & \multicolumn{3}{|c|}{ Pre-intervention } & \multicolumn{3}{|c|}{ Post-intervention } & \multirow{2}{*}{$p$-value } \\
\hline & Mean & SD & Min-Max & Mean & SD & Min-Max & \\
\hline Preparation of the client & 3.06 & $+/-1.711$ & $0-6$ & 4.23 & $+/-2.362$ & $0-7$ & $.005 *$ \\
\hline Preparation of the environment & 1.87 & $+/-0.922$ & $0-4$ & 2.58 & $+/-1.148$ & $0-4$ & $.002 *$ \\
\hline Position of the patient & 7.16 & $+/-2.491$ & $0-9$ & 8.42 & $+/-1.089$ & 5-9 & $.007^{*}$ \\
\hline Device maintenance & 2.87 & $+/-1.258$ & $0-5$ & 4.42 & $+/-1.057$ & $2-6$ & $.001 *$ \\
\hline Determining and recording values & 15.65 & $+/-1.624$ & $13-20$ & 16.9 & $+/-1.972$ & $13-20$ & $.006 * *$ \\
\hline
\end{tabular}

*Wilcoxon test for paired samples; ** Paired $t$ test.

Table 3. Comparison of the frequency of correct answers provided by nurses in the theoretical assessment concerning the steps of blood pressure measurement $(\mathrm{n}=31)$

\begin{tabular}{|c|c|c|c|c|c|c|c|}
\hline \multirow{2}{*}{ Steps of BP measurement } & \multicolumn{3}{|c|}{ Pre-intervention } & \multicolumn{3}{|c|}{ Post-intervention } & \multirow{2}{*}{$p$-value } \\
\hline & Mean & SD & Min-Max & Mean & SD & Min-Max & \\
\hline Preparation of the client & 2.65 & $+/-1.253$ & $0-5$ & $4.32 *$ & $+/-1.301$ & $1-6$ & $.001^{*}$ \\
\hline Preparation of the environment & 1.84 & $+/-0.820$ & $0-3$ & $3.19 *$ & $+/-0.703$ & $2-4$ & $.001 *$ \\
\hline Position of the patient & 2.81 & $+/-0.792$ & $1-4$ & $4.16^{*}$ & $+/-0.820$ & $3-6$ & $.001^{*}$ \\
\hline Device maintenance & 3.55 & $+/-1.546$ & $1-7$ & $5.68^{*}$ & $+/-0.945$ & $4-8$ & $.001^{*}$ \\
\hline Determining and recording values & 4.10 & $+/-1.221$ & $2-6$ & 5.65 & $+/-0.551$ & $4-6$ & $.001^{* *}$ \\
\hline
\end{tabular}

*Wilcoxon test for paired samples; ** Paired $t$ test. 


\section{Discussion}

The results of the current study show that about one-third of the participants were trained in the measurement of BP after their formal education, suggesting a lack of importance for institutions, and possibly nurses, in obtaining correct BP measurements.

It is known that continuing education is essential to improving professional performance, especially in the detection of hypertension. ${ }^{[6]}$ Previous research has shown a lack of knowledge in undergraduate nursing students, ${ }^{[9,15]}$ reinforcing the need for regular training and updates. Therefore, it is necessary to alert managers and nursing schools to the need to seek educational programs for professionals in order to provide safer patient care. ${ }^{[4,16]}$

In this study, the use of clinical simulation of a nursing technique contributed strongly to attaining the proposed objectives. The simulation gave the participants the opportunity to spontaneously self-assess any problems relating to the clinical practice of obtaining indirect BP measurements and started a discussion of the problems relating to their experiences in clinical practice. In a previous study, simulation has proven to be effective in teaching the indirect BP measurement for students in health related fields. ${ }^{[17]}$

Similarly, another study allowed researchers to evaluate the applicability of simulation in education as a way of improving the search for higher quality of care, as there is strong evidence that its use is beneficial to patient safety. ${ }^{[18]}$ Yet another study showed that real/actual patient simulation can be used successfully as an instructional method in nursing education and can be a valuable tool. ${ }^{[19]}$ Nursing educators are challenged with discovering ways to facilitate the education of their students and real-life patient simulation can be used effectively for this purpose.

In regards to the preparation of the patient for BP measurement, the mean of correct answers increased in both the practical and theoretical assessments. Significant improvement was also observed in theoretical and practical knowledge concerning preparation of the setting, in accordance with guidelines..$^{[7,20]}$ Also, nurses need to pay attention to and attempt to enable the environment to have a pleasant temperature. ${ }^{[8]}$

Concerning the position of the patient, significant improvement was noted in theoretical and practical knowledge. However, we observed that professionals faced difficulties in describing slight arm flexion, in addition to keep it supported and with palm facing up, even after intervention, suggesting the need to emphasize training especially in keeping the patient's arm supported. ${ }^{[7]}$
The results of this study show that the professionals were aware of the need to keep the patient's arm at heart level. A previous Brazilian study with nurses and physicians also provided similar results to this current study. ${ }^{[21]}$ However, another Brazilian study reported opposite results within a similar population. ${ }^{[22]}$ This step is critical, because failing to have the arm at heart level can strongly interfere with the results obtained and thus needs to be strictly observed. Lack of theoretical and practical knowledge was observed among the professionals before the intervention concerning device maintenance. Similar to a previous study, ${ }^{[23]}$ the professionals presented an important knowledge deficit concerning device calibration and ideal cuff size.

Important improvements were observed in the practical and theoretical assessments after the intervention, especially regarding the choice of appropriate cuff sizes and correct positioning of the patient's arm. In contrast, the step check the device calibration schedule was neglected after the intervention, a similar result was observed among other ICU nurses. ${ }^{[24]}$ Equipment calibration is essential to obtain accurate BP values; the responsibility to ensure periodical calibration should be shared and professionals have to be aware of the schedule and conditions of calibration, as well as proper storage and packing of the equipment. Institutions play a key role in the management of acquiring and maintaining equipment, including keeping a calibration schedule, and qualifying professionals to check, handle, and dispose of devices. ${ }^{[25]}$

The choice of a cuff that corresponds to $40 \%$ of the patient's brachial circumference was seldom mentioned in the theoretical assessment, which matches with another similar study. [21] This step was also neglected in the practical assessment, suggesting a need to reflect upon the potential causes of such a gap in knowledge. In this study, the step improved after the intervention. A lack of different cuff sizes is a challenge to be overcome throughout the world ${ }^{[25]}$ because it may induce the professional to only use the one that is most accessible and consequently obtain hyper- or hypo-estimated BP values, gradually no longer taking the importance of this step into consideration. An investment from both professionals and institutions is required to change this context and provide different cuff sizes that meet the physical parameters of patients.

Concerning the step determining and recording values, the results of the practical assessment showed significant improvement, similar to the theoretical assessment, especially in regards to avoiding rounding values, in accordance with a study conducted with nurses from the United States. ${ }^{\left[{ }^{[6]}\right.}$ Such a practice may be related to the use of automatic devices in 
which it is routine to record values in $\mathrm{mmHg}$ directly onto the patient's chart.

The educational intervention was effective in improving theoretical and practical knowledge of professionals regarding the indirect measurement of BP. Despite the statistically significant results, generalization is not advisable due to the sample size. The study, however, can and should be replicated as an alternative strategy to qualifying nurses, since it was validated in regular physical and functional-structure conditions of a Brazilian public hospital. Even though the participants were asked not to share the studied experience with their participant co-workers, this could not be systematically controlled.

\section{Conclusions}

The educational intervention improved the theoretical and practical knowledge of the studied sample concerning the indirect measurement of BP. It also encouraged criticalreflective awareness of the need to seek updated scientific evidence for professional development. Additionally, it favored understanding of the management of equipment in a hospital facility, shared responsibility in calibration-control, and device maintenance. Therefore, a high level of knowledge for nurses should be associated with physical settings that are compatible, organized, and with an appropriate policy of equipment management manifesting a culture that regularly updates professionals' knowledge concerning clinical guidelines and evidence-based practice.

\section{Strengths and limitations}

This study used an evidence-based educational intervention to improve nurses' practical and theoretical knowledge regarding the indirect measurement of BP in a cardiac unit. We hope that by sharing our learning experiences, more nurses will be given similar opportunities using the strategies presented in this article.

The limitations of the present study include: the sample size being restricted to one particular health service, difficulties in making comparisons with experiments with groups of nursing professionals, and there is a need for other studies that validate the English-language CTIM-PA questionnaire in other populations.

\section{ACKNOWLEDGeMENTS}

Professionals who participated in the study and the staff for data collection. Coordination of Improvement of Higher Level Personnel (CAPES)/Brazil-for granting the scholarship.

\section{Conflicts of InTEREST Disclosure}

The authors declare that there is no conflict of interest.

\section{REFERENCES}

[1] World Health Organization. World Health Day 2013. A global brief on hypertension: silent killer, global public health crisis. Geneva: World Health Organization. 2013.39 p.

[2] Elliott M, Coventry A. Critical care: the eight vital signs of patient monitoring. British Journal of Nursing. 2012; 21(10): 621625. PMid:22875303 https://doi.org/10.12968/bjon. 2012 .21 .10 .621

[3] National Guideline Clearinghouse. Guideline summary. Clinical practice guideline: non-invasive blood pressure measurement with automated devices. Rockville (MD): Agency for Healthcare Research and Quality (AHRQ): 2012. 13 p.

[4] Leung AA, Daskalopoulou SS, Dasgupta K, et al. Hypertension Canada's 2017 guidelines for diagnosis, risk assessment, prevention, and treatment of hypertension in adults. Canadian Journal of Cardiology. 2017; 33(5): 557-576. PMid:28449828 https ://doi .org/10 $.1016 /$ j.cjca. 2017.03.005

[5] Mancia G, Fagard R, Narkiewicz K, et al. 2013 ESH/ESC Guidelines for the management of arterial hypertension: the Task Force for the management of arterial hypertension of the European Society of Hypertension (ESH) and of the European Society of Cardiology (ESC). Journal of Hypertension. 2013; 31(7): 1281-1357. PMid:23817082 https://doi.org/10.1097/01.hjh.0000431740.32696.cc

[6] Campbell NR, Berbari AE, Cloutier L, et al. Policy statement of the world hypertension league on noninvasive blood pressure mea- surement devices and blood pressure measurement in the clinical or community setting. Journal of Clinical Hypertension (Greenwich) 2014; 16(5): 320-322. PMid:24811572 https://doi.org/10.1 $111 / \mathrm{jch} .12336$

[7] Brazilian Cardiology Society. [VII Brazilian Guidelines on Hypertension]. Arquivos Brasileiros de Cardiologia. 2016; 107(3Suppl.3): $1-83$.

[8] Ritchie LD, Campbell NC, Murchie P. New NICE guidelines for hypertension. BMJ. 2011; 343: 5644. PMid:21900351 https: //doi.org/10.1136/bmj.d5644

[9] Machado JP, Veiga EV, Ferreira PAC, et al. Theoretical and practical knowledge of Nursing professionals on indirect blood pressure measurement at a coronary care unit. Einstein. 2014; 12(3): 330-335. PMid:25295455 https ://doi .org/10.1590/S1679-4 $5082014 A 02984$

[10] Andrade LZC, Freitas DT, Holanda GF, et al. [Development and validation of an educational game: blood pressure measurement] Revista de Enfermagem UERJ. 2012; 20(3): 323-327.

[11] Eslamian J, Moeini M, Soleimani M. Challenges in nursing continuing education: A qualitative study. Iranian Journal of Nursing and Midwifery Research. 2015; 20(3): 378-386. PMid:26120340

[12] Deon KC, Santos DMSS, Reis RA, et al. Translation and cultural adaptation of the Brazilian version of DISABKIDS $₫ *$ Atopic Dermatitis Module (ADM). Revista da Escola de Enfermagem USP 
2011; 45(2): 450-457. PMid:21655797 https://doi.org/10.1 590/S0080-62342011000200021

[13] Cyrino EG, Toralles-Pereira ML. Discovery-based teaching and learning strategies in health: problematization and problem-based learning Cadernos de Saúde Pública. 2004; 20(3): 780-788. PMid:15263989 https://doi.org/10.1590/S0102-311X2004000300015

[14] Bingham AL, Sen S, Finn LA, et al. Retention of advanced cardiac life support knowledge and skills following high-fidelity mannequin simulation training. American Association of Colleges of Pharmacy. 2015; 79(1): 12. https://doi.org/10.5688/ajpe79112

[15] Bland M, Ousey K. Preparing students to competently measure blood pressure in the real-world environment: a comparison between New Zealand and the United Kingdom. Nurse Education in Practice. 2012; 12(1): 28-35. PMid:21641869 https ://doi.org/10.1016/j.ne pr. 2011.04.009

[16] Leblanc ME, Cloutier L, Veiga EV. Knowledge and practice outcomes after home blood pressure measurement education programs. Blood Pressure Monitoring. 2011; 16(6): 265-269. https://doi . org/10.1097/MBP . Ob013e32834b667a

[17] Lee JJ, Sobieraj DM, Kuti EL. Student measurement of blood pressure using a simulator arm compared with a live subject's arm. American Association of Colleges of Pharmacy. 2010; 74(5).

[18] Killam LA, Montgomery P, Raymond JM, et al. Unsafe clinical practices as perceived by final year baccalaureate nursing students: Q methodology. BMC Nursing. 2012; 11: 26. PMid:23181662 https://doi.org/10.1186/1472-6955-11-26

[19] Brewer EP. Successful techniques for using human patient simulation in nursing education. Journal of Nursing Scholarship. 2011; 43(3): 311-317. https://doi.org/10.1111/j.1547-5069.20 $11.01405 . \mathrm{x}$
[20] James PA, Oparil S, Carter BL, et al. Evidence-based guideline for the management of high blood pressure in adults: report from the panel members appointed to the Eighth Joint National Committee (JNC 8). JAMA. 2014; 311(5): 507-520. PMid:24352797 https://doi.org/10.1001/jama.2013.284427

[21] Rabello CC, Pierin AM, Mion D. [Healthcare professionals' knowledge of blood pressure measurement]. Revista da Escola de Enfermagem USP. 2004; 38(2): 127-134. https ://doi.org/10.1590/ S0080-62342004000200002

[22] Veiga EV, Nogueira MS, Cárnio EC, et al. Assessment of the techniques of blood pressure measurement by health professionals. Arquivos Brasileiros de Cardiologia. 2003; 80(1): 89-93, 83-88. https://doi.org/10.1590/S0066-782X2003000100008

[23] Almeida TC, Lamas JL. Nurses of adult intensive care unit: evaluation about direct and indirect blood pressure measurement]. Revista da Escola de Enfermagem USP. 2013; 47(2): 369-376. https : //doi.org/10.1590/S0080-62342013000200014

[24] Freire RP, Pitassi C, Gonçalves AA, et al. Gestão de equipamentos médicos: o papel das práticas de qualidade em um hospital de excelência brasileiro. Revista de Administração Hospitalar e Inovação em Saúde. 2012; 1: 13.

[25] Veiga EV, Arcuri EA, Cloutier L, et al. Blood pressure measurement: arm circumference and cuff size availability. Revista Latino Americana de Enfermagem. 2009; 17(4): 455-461. PMid:19820850 https ://doi.org/10.1590/S0104-11692009000400004

[26] Dickson BK, Hajjar I. Blood pressure measurement education and evaluation program improves measurement accuracy in communitybased nurses: a pilot study. Journal of the American Academy of Nurse Practitioners. 2007; 19(2): 93-102. PMid:17300535 https : //doi.org/10.1111/j.1745-7599.2006.00199.x 